\title{
War and Journalism: Framing the Syrian and Yemen War Through the New York Times Online News Coverage
}

\author{
Hatem Alsridi* Abdul-karim Ziani \\ Dep. Of Mass Communication, University of Bahrain, P.O. Box 32038, Kingdom of Bahrain
}

\begin{abstract}
This study, based on a quantitative and qualitative approach of content analysis, aims to understand the image of Arab-Muslims in times of crises and wars and how they are presented through the American press. In particular, the study is concerned with analyzing the news coverage of current Arab issues by the New York Times Online (NYT). The study answers a number of questions about how the New York Times Online produced stories and news related to the Syrian war (SW) and the Operation Decisive Storm (ODS) in Yemen, in terms of news processing and media frames.Results revealed that overall, the perceptions of news-sources trends in the NYT regarding the two issues (SW and ODS) can be described as negative trends. Furthermore, the analysis framing perspective indicated that the NYT was more likely to use emotional features than substantive features to cover all the two issues. The type of frame most used in covering the SW was limited frame, conflict frame, general frame and human-interest frame, while framing type related to the ODS, the most frame used were conflict frame, human-interest frame and limited frame.
\end{abstract}

Keywords: journalism, war, news coverage, framing, Syria, Yemen, New York Times

DOI: $10.7176 / \mathrm{NMMC} / 88-03$

Publication date: February $29^{\text {th }} 2020$

\section{1- Introduction}

The media is increasingly interested in covering wars, conflicts, and crises, however, the coverage is usually incomplete or involves many disadvantages, due to the ethnic bias of journalists, the monitoring of the press by the military, the heavy reliance on official sources, and the lack of critical reports (Lee, 2004).

The relationship between governments and the media in times of crises and wars remains characterized by conflicts of interest (Biernatzki, 2003). Governments try to conceal at least some information to protect their forces from enemy actions and to ensure the success of their mission, while the media is obligated according to professionalism to obtain the maximum amount of Information and disseminate it. However, the rapid development of technology in its relationship with the media has increased the conflict, thanks to the speed in the broadcast of news and information and the multiple ways of spreading it through digital media platforms and social networks.

As far as the Arab level is concerned, the war in Syria and Yemen in the last decade has been one of the most important Arab issues, which has received a large part of Western media coverage. This coverage has undoubtedly had an impact on the perception and views of Western media audience regarding the events and issues in the Arab region. Some Western media have considered that the wars in Syria and Yemen are actually proxy wars (Karakir, 2018), fueled by influential international and regional powers in the Middle East and the world. Another part of the Western media has considered the war in Syria an extension of what is known as the "Arab Spring". Meanwhile, the Western media have different and contradictory media frames according to the country's accounts or the political trends of the media itself (Simons, 2016, Vis, 2016).

Media coverage was also influenced by NGOs' discourse on wars and crises, especially the war in Syria and Yemen, and, thus, played a major role in shaping foreign policy positions of States and contributing to the establishment of specific media frames. For example, major international NGOs such as Amnesty International and Human Rights Watch have remained the most influential in providing normative frames and calling for a firm stance towards the Assad regime (Meyer et al, 2018).

The influence of the media on public opinion through the media frames that they create through press coverage is part of many research and theories. Lippmann (1922) talked about the role of the press in making certain frames, saying that "The way in which the world is imagined determines at any particular moment what men will do. ", and it is believed that " People get most information about public affairs from the news media which, over time, creates a frame of expectation, or dominant frame". Other researchers have focused on the importance of the media in prioritizing people's interests through news coverage (McCombs and Shaw, 1972), the influence of framing on public opinion (Chong and Drukman, 2007) and the role of traditional and new media in framing minds (Castells, 2013).

This study falls within the literature on the framing theory, which through its concept can make the strength of the frame with the same as the strength of the language used in the communication process (Entman, 1993). Framing can be determined in four basic points: (1) communications that form private beliefs consciously or unconsciously, (2) texts containing key words, ideas, stereotypes, images, sources of facts and judgments, (3) the 
receiver whose frames may differ from text or media frames, and (4) the culture that forms the most used frame bank.

The study of frames aims to identify patterns in the interpretation of issues and also make comparisons between the types of media coverage (Elzahar, 2018), where the researcher selects the issue, along with a media frame that can only be seen when there is a problem. Then the researcher must define specific situations when studying how the frames affect public opinion, followed by the stage of identifying the primary frames for forming the coding system. Finally, the frames are analyzed through a sample of the media outlets (Chong and Druckman, 2007).

This study aims to analyze the image of Arab-Muslims within the American media coverage and the media frames that were made through the New York Times Online coverage of the SW and the ODS in Yemen.

\section{2- Related Work}

The issue of the SW and the ODS in Yemen has been the subject of analysis of many media studies and researches that have paid attention to its various aspects, such as styles of news coverage, and ways of framing and influencing public opinion. A study analyzing elite journalism in the United States of America and its role in framing the international response to Syria's use of chemical weapons (Cozma \& Kozman, 2015) found that the stories in the month following the event focused mainly on diplomatic efforts and stopped paying attention to the civil war, while continuing to frame the dominant conflict. The analysis also supports the literature on the relationship between determining the sources and the framing.

Brown (2016) analyzed the news coverage of the incidents of the chemical weapons use in the Syrian Ghouta region by the Russian media versus news coverage in the United States and France. The differences lie in three basic levels: (1) details and style of coverage, (2) attribution of responsibility and assessment of motives, and (3) representation of the roles of Russia and Western powers. The study also stated that the discrepancies identified in the analysis of news coverage resulted from a contradiction in the narratives between Russia and the Western powers.

In a comparative analysis of a study on the frames used in opinion articles for antiwar.com and cnn.com on the war in Syria (Alitavoli, 2019), based on Entman's framing theory, concluded that cnn.com provided frames that featured Bashar al-Assad as "evil and monster" who strikes his people with chemical weapons, and at the same time it provided frames that confirmed Barack Obama's inefficiency in implementing a strategic plan on the war in Syria. On the other hand, antiwar.com provided frames that encouraged readers to protest against another war, and reminded them of the failures of similar previous wars such as the Iraq war and its negative legacies.

It is certain that news has been used extensively in the Syrian conflict in an attempt to influence public opinion towards allowing "humanitarian intervention" in the form of another military war (Simons, 2016). The results of another study (Godefroidt et al., 2016) raised questions about the neutrality of newspapers and their impact on public opinion in France, Britain, the United States of America and Russia through the newspapers coverage in these countries for the war in Syria before and after the use of chemical weapons in 2013. The national frame was the predominant one, followed by both the liability and conflict frame, whereas, despite the great impact of the conflict, frames of ethics, human interests and economic impact did not exist.

On the visual framing of the conflict in Syria, Greenwood (2015) analyzed 193 photographs that were published in news magazines and magazines of public affairs between 2011- 2013. The results confirmed the dominant visual frame of the conflict through pictures of fighting and victims, but also indicated that public affairs magazines published a higher percentage of pictures depicting the peace frame.

A study on analyzing the frames used in the Yemen war (Elzahar, 2018) via media coverage of four television channels (Al-Arabiya, Al-Jazeera, Russia Today and BBC Arabic) showed that the predominant frame in all channels is the frame of conflict, followed by the frame of human interests, while The ethics frame is the lowest frame used in all channels.

A study of framing disputed accounts in the Saudi News Agency, the Tehran Times, and Saba News, about the war in Yemen, emphasized the use of basic concepts of regional conflict, terrorism, and the humanitarian crisis. On the other hand, each agency dealt with these concepts through its different framing of conflict, which served as major points of contention between them (Vis, 2016).

The framing theory remains among the most important theories of mass communication used in the research. Researchers interest more and more about how the media packages and presents information to the public, and how the media highlights certain events and then places them within a particular context to encourage or discourage certain interpretations. In this way, the media exercises a selective influence on how people view reality (Communication Studies, 2019).

\section{3- Research Questions}

Further, this paper particularly seeks to understand the Arab-Muslims and how they are presented in the US 
media, particularly online newspaper, and looks at its coverage of some current Arab issues by attempting to answer the following questions. How does the New York Times (NYT) produce news and stories about the Syrian War (SW) and Operation Decisive Storm (ODS) in terms of: (1) form of news treatment; (2) news treatment; and (3) news-treatment frame?

\section{4- Method}

The research approach adopted here integrated two different stages of newspaper analysis. First, a descriptive and quantitative approach of content analysis was selected as the best method of ascertaining the volume and nature news coverage of Arabs' related matters in the US media. This approach has been found to be highly useful for tracing key presentational and format features of newspaper coverage over time. Although it is predominantly a quantitative research tool, this approach also informed the second stage of content analysis undertaken by this study - a qualitative analysis of the thematic elements of The NYT covering some current Arab-Muslims issues in the Middle East. The analysis focuses on one of the leading sources of newspapers in the US, the NYT. The choice of this newspaper as the focus of this study reflects our contention that media is both a significant source of cultural production and an important source of information, not only in the US, but it also in global audiences in situations (e.g., news coverage) in which they 'do not' have direct access. The NYT was chosen, therefore, for its national and international reputation, and its popularity in covering issues related to Arabs and Muslims in the US and globally.

Regarding the sampling, the analysis selected (both quantitative and qualitative approaches) a completely random sample of stories and news materials from the NYT website regarding the two main issues (SW and ODS). Samples covered were depended on the main issues. For example, the sample of SW was taken from January 1st, 2011 to December 31st, 2016, while the ODS was from March 2015, as this time when the operation started. A total of 756 news stories related to the above issues was content-analyzed. Each news story was coded based on three main elements: (1) form of news treatment (e.g., form of picture used); (2) news treatment (e.g., news-source trends, news sources, topics, key figures, type of news treatment, aims of news treatment); and (3) news frame (e.g., framing type, mechanisms frame, strategies of news frame, responsibility frame, portrayal).

Regarding the units of analysis, the unit of analysis used here was the entire news story (news, reports, articles, interviews, etc.) in addition using subject, idea and word units to analyze the news frames. In order to gather the data, the main search phrase/term utilized for the two issues was "Syrian War", "Operation Decisive Strom", "Yemen War", "Saudi and Yemen War". These phrases/terms ensured that, as many articles, stories and news as possible pertaining to Arabs were included in the story or news topic. The population was directly drawn from a search of NYT website for the period mentioned above, after subscription fees were paid.

The qualitative variables that were analyzed include (1) the Tone: the mood or pitch of the story (positive, negative or neutral tones), (2) the Themes: a close reading was undertaken of all the themes that emerged within the total sample of newspaper coverage analyzed.

The results of content analysis (quantitative and qualitative) of data analysis were manually coded in spreadsheet format. For the quantitative approach, SPSS was used to generate the descriptive statistical findings and focused more on questions relating to what. As stated above, the quantitative findings were analyzed in order to trace the descriptive and presentational coverage trends by the NYT. On the other hand, the qualitative approach was used to focus on the explicitly on questions relating to how. Is the image of Arab and Muslims (news) in the NYT primarily negative, as is commonly perceived? If so, what evidence can support this? The following discussion outlines the findings that emerged from this analysis regarding the Arab and Muslim news in the US media.

Practically, before the analysis took place, the coding sheet (quantitative and qualitative) was tested to ensure that all the categories and sub-categories were consistent with the study aims. In doing so, a high reliability of coding was done via two academic researchers. Comparing the results of the two coders, it was found that they mostly reached the same results except for slight differences in the total sheet. The coders achieved 84 percent agreement in all the categories, which is within the acceptable range for content analysis (Holsti, 1969).

\section{5- Findings}

\section{5-1- Form of News Treatment}

In terms of the form of picture used by the NYT, the results showed that the newspaper used different types of pictures. To cover the SW, the newspaper often used feeds/maps $(32.1 \%)$ and then objective pictures $(27.7 \%)$, characterized pictures $(25.2 \%)$, while less graphic pictures $(11.8 \%)$, cartoons $(2.5 \%)$ and logos were used. Regarding the ODS, most the form of pictures were based on feeds/maps (29.2\%), followed by objective pictures $(23.5 \%)$, graphic pictures $(22.5 \%)$, characterized pictures $(22.3 \%)$, while again less used of logos $(1.5 \%)$ and cartoons $(1 \%)$ by the NYT. The results indicated that the NYT used different form of pictures when it comes to cover issues related to the Arab world and their matters. 
The NYT used different techniques or style to highlight the coverage of news and stories related to the two issues. To cover the SW, the NYT used again more information, videos and graphics $(37.3 \%)$ and links or referrals $(34.9 \%)$. Less used were multi-media platforms $(18.5 \%)$ and multi-texts $(9.2 \%)$. It seems the NYT used similar style to highlight the news coverage of ODS, with most likely to use links or referrals (32\%), multimedia platforms (28\%) and information, videos and graphics $(22.1 \%)$.

\section{5-2- News Treatment}

The NYT was more likely to used negative trends when they covered the two issues. For example, when it comes to the SW and ODS, the NYT was more likely to be 'slanted' and produced negative trends $(87 \%$ and $87.9 \%$ respectively). Less positive trends were placed again to cover the two issues.

Overall, the perceptions of news-sources trends in the NYT regarding the two issues (SW and ODS) can be described as negative trends (as it proves by the quantitative approach). This is an important investigation, as it is a widely help to see how the NYT presents news and stories related to Arabs and Muslims. From the qualitative perspective, examples of negative trends include deceptions like:

"The day broke over a landscape of grief as mourners set out for funerals in the southern towns of Sanamayn and Dara'a, in Latakia, in the central city of Homs and in the suburbs of Damascus. In each place, demonstrators had been killed hours earlier, shot by government forces in the most violent government oppression since 1982, when the leadership killed at least 10,000 people in the northern city of Hama." [Michael Slackman and Liam Stack, MAR. 26, 2011]

"As the shelling of infrastructure and the killing of civilians continues, Yemen is coming apart. Hunger is pervasive; major cities have become ghost towns. The bombing campaign will not resolve our four-year-old political crisis; it will only erode any modicum of national cohesion left. When the intervention ends, Al Qaeda in the Arabian Peninsula will step into the vacuum left by the chaos and by the government's weakness, especially in southern cities like my hometown, Taiz." [Bushra alMaqtari APR. 14, 2015]

The study also examined the type of news sources the NYT often used to cover the two issues. To cover the SW, the NYT used 'no mentioned the sources' (13.1\%), 'eye witness' (11\%), 'Arabic news agencies' (10.8\%), 'official sources' $(10.3 \%)$ and 'social media sites' $(9.9 \%)$. Other news sources were less used here again. To cover the ODS, the NYT often used 'other sources' (13.5\%), 'eye witness' (13.4\%), 'social media sites' (12.3\%), 'correspondents' (12.2\%), 'no mentioned the sources' $(11.9 \%)$ and 'national news agencies' $(10 \%)$.

The qualitative analysis revealed that most news sources were used by the NYT to cover news and stories regarding the two issues were 'social media sites', 'official sources', 'experts' and 'no mentioned sources'. Examples where such as:

"Late Wednesday, Yemeni bloggers shared images and video on Twitter and Facebook said to show massive fires after coalition airstrikes on a military base in Taiz seized earlier in the day by the Houthis." [Robert Mackey APR. 22, 2015]

"In an interview published Monday in the Financial Times, President Dmitri A. Medvedev of Russia practically ruled out support for such a resolution, saying he fears it "may state one thing but the resulting actions may be quite different." [Thom Shanker, JUN. 19, 2011]

"The assertion that there is evidence suggesting the rebels have used sarin was made by Carla Del Ponte, a former chief prosecutor for international criminal tribunals that investigated Rwanda and the former Yugoslavia who is now serving on a commission looking into human rights abuses in Syria." [Mark Landler and Eric Schmitt, MAY. 6, 2013]

The analysis framing perspective revealed that different features (e.g., substantive and emotional) were used by the NYT when covering and producing news and stories related to the two issues. In our research, however, the NYT was more likely to use emotional features than substantive features to cover all the two issues. The majority of the news and stories (around 60\%) covering the two issues was relied on emotional features, while nearly $40 \%$ of the news and stories relied on substantive features.

The qualitative analysis provided proven on how the NYT used these perspective frames. These were, for example,

"Thousands of Syrians, mostly civilians, have been killed by security forces since the uprising started last March as a peaceful protest against Mr. Assad's autocratic rule, energized by the Arab Spring democracy revolts in Tunisia, Egypt and Libya." [Rick Gladstone, MAR. 5, 2012]

"There was no sign of any imminent troop deployment Thursday, and both Egypt and Saudi Arabia have painful memories of previous excursions into Yemen's mountainous desert. But many analysts have already warned that airstrikes by a coalition led by the Saudis are unlikely to defeat the Houthiallied forces without ground troops. "[David D. Kirkpatrick MAR. 26, 2015]

The results indicated that the NYT used different news topics when covering the two issues. For example, to cover news topics related to the SW, again human rights issues $(40.2 \%)$, security/military topics $(20.2 \%)$ and 
humanity (19.4\%) were more likely to be mentioned than other topics. While the most news topics covered the ODS were security/military $(22.1 \%)$, human rights issues $(19.9 \%)$ and political topics $(18.2 \%)$. Other topics were less mentioned here.

The qualitative analysis revealed that different news topics were highlighted by the NYT when covering the two issues. These were, for example, related to corruption and economic, terrorism, security/military, human rights issues and humanity. Terrorism is often a hot topic in different news media. In this analysis, the NYT was found to mention this term quite often with covering the two issues (SW and ODS) as following:

"SANA said the judge, Abad Nadhwah, died instantly when a remotely detonated bomb exploded under his car. On Tuesday, SANA said gunmen assassinated Mohammad Osama al-Laham, a prominent agricultural expert and brother of the Syrian Parliament speaker, in a central Damascus neighborhood while he was driving to work. The news agency attributed both assassinations to terrorists, the government's catchall term for Mr. Assad's opponents. " [Neil MacFarquhar and Rick Gladstone, NOV. 7, 2012]

"His comments were one of several indications on Thursday that the antagonists on either side of the Yemeni conflict are bracing for a prolonged battle as Yemen - like Iraq, Libya and Syria - is consumed by civil conflict, regional proxy wars and the expansion of extremist groups like the Islamic State and Al Qaeda." [David D. Kirkpatrick MAR. 26, 2015]

The analysis also revealed that the NYT often used security/military topic when covering issues related to both issues (SW and ODS) such as:

"The Syrian government tried to ease a grave political crisis on Sunday by blaming armed gangs for killing 12 people in the northwestern port city of Latakia in previous days and promising to soon lift a draconian emergency law that allows the government to detain people without charges." [Michael Slackman, MAR. 27, 2011].

"Residents of Sana said the Dailami air base and the city's international airport had been hit. Antiaircraft gunfire continued for hours, and residents said they saw flames rising from both structures." [David D. Kirkpatrick MAR. 26, 2015]

The NYT also mentioned human rights issues when covering the two issues. To cover the SW, examples were such as:

"The implications of this surge in the proportion of children and women on the move are enormous - it means more are at risk at sea, especially now in the winter, and more need protection on land," warned Marie-Pierre Poirier, Unicef's special coordinator for the refugee and migrant crisis in Europe." [The Editorial Board FEB. 10, 2016]

"[...] Human Rights Watch said civilians faced grave threats because of the clashes. The group cited abuses by the pro-Houthi fighters, including the killing of two women last month and detentions of local aid workers, as evidence of possible war crimes committed by the combatants." [Ben Hubbard and Kareem Fahim MAY. 7, 2015]

The key figures were used by the NYT to cover news and stories related to the SW, the newspaper was more likely to use military/security figures (30\%), activists (22\%) and non-official figures $(21.3 \%)$. Similar result was found to cover the ODS, with focusing on military/security figures $(35.1 \%)$, activists $(27.8 \%)$ and non-official figures $(26.1 \%)$.

The qualitative analysis revealed the most key figures were presented by the NYT were official, military/security and activists. Examples of these were:

"In Damascus, the government's chief spokeswoman, Bouthiana Shaaban, told reporters that the president would soon move to lift the emergency law, though she did not say when." [Michael Slackman MAR. 27, 2011]

"In an interview on Monday, Brig. Gen. Ahmed Asiri, a spokesman for the Saudi-led coalition, defended its progress, saying that the bombing had degraded the Houthis' military strength and destroyed many of their heavy weapons while helping Yemen's president, Abdu Rabbu Mansour Hadi, build a government in exile." [Shuaib Almosawa and Ben Hubbard JUN. 24, 2015]

"What will change is nothing," said Radwan Ziadeh, a Syrian human rights activist and legal expert now teaching at George Washington University. " [Michael Slackman MAR. 27, 2011]

The NYT often used different type of news treatment when they dealing with the two issues. For example, it used mostly a narrative style to cover the SW and ODS ( $81.9 \%$ and $65.8 \%$ respectively).

The aims of news treatment of two issues were differently found. For example, to cover the SW and ODS, the NYT often used explanatory treatment $(63.9 \%$ and $60.7 \%$ respectively) and less often critical $(28.7 \%$ and $36.2 \%$ respectively) and propaganda treatment ( $7.4 \%$ and $3.1 \%$ respectively). 


\section{5-3- News-Treatment Frames}

Table 1. Type of Frames

\begin{tabular}{|l|c|c|c|c|}
\hline & \multicolumn{2}{|c|}{ SW } & \multicolumn{2}{c|}{ ODS } \\
\hline Conflict & $N$ & $\%$ & $N$ & 20.6 \\
\hline Responsibility & 103 & 19.1 & 116 & 17.1 \\
\hline Economic result & 86 & 16.0 & 96 & 8.0 \\
\hline Human interest issues & 37 & 6.9 & 45 & 19.4 \\
\hline General frame & 97 & 18.0 & 109 & 15.8 \\
\hline Limited frame & 102 & 18.9 & 89 & 19.0 \\
\hline Total & 114 & 21.2 & 107 & 100 \\
\hline
\end{tabular}

The type of frame most used in covering the SW was limited frame (21.2\%), conflict frame (19.1\%), general frame $(18.9 \%)$ and human-interest frame $(18 \%)$, while framing type related to the ODS, the most frame used were conflict frame (20.6\%), human-interest frame (19.4\%) and limited frame (19\%).

"The officials said the effort was part of a broader government campaign to increase pressure on the Syrian leader as his security forces continue to kill and wound protesters.” [Thom Shanker JUN. 19, 2011]

"The air campaign has also created fissures among the Houthis and loyalists to the former Yemeni president, Ali Abdullah Saleh. Mr. Jubeir said the bombing had prompted some senior Yemeni officers - he did not say how many - to abandon Mr. Saleh.” [Michael R. Gordon and Eric Schmitt APR. 15, 2015]

"An additional 1.7 million Syrians have left the country, according to tabulations by the United Nations refugee agency, though the State Department official noted that the actual number could be higher." [Michael R. Gordon JUL. 18, 2013]

Table 2. Mechanisms Framing

\begin{tabular}{|l|c|c|c|c|}
\hline & \multicolumn{2}{|c|}{ SW } & \multicolumn{2}{c|}{ ODS } \\
\hline & $\mathrm{N}$ & $\%$ & $\mathrm{~N}$ & 48.2 \\
\hline Transferring facts & 89 & $26.0 \%$ & 109 & $48.2 \%$ \\
\hline Provided one view & 197 & 57.6 & 78 & 34.5 \\
\hline Provided multi views & 56 & 16.4 & 39 & 17.3 \\
\hline Total & 342 & 100 & 226 & 100 \\
\hline
\end{tabular}

Different mechanisms were used by the NYT in framing news and stories related to the two issues. For example, to cover the ODS, the NYT often used 'transferring facts' $(48.2 \%)$ and 'one view' mechanisms $(34.5 \%)$ and 'multi views' mechanisms (17.3\%).

It noticed also that the NYT provided one view when covering the two issues (qualitative analysis). For example, to cover the SW, examples were such as:

"The coastal town of Latakia was sealed off by security services and the military one day after witnesses and human rights groups reported that government forces opened fire on demonstrators." [Michael Slackman MAR. 27, 2011]

"Saudi Arabia has no right to attack the Yemenis or even to give them any kind of truce," he added [Basem al-Houthi]. "There is no trust in this regime at all." [Ben Hubbard and Kareem Fahim MAY. $7,2015]$

Table 3. Strategies of Strengthening News Frame

\begin{tabular}{|l|c|c|c|c|}
\hline & \multicolumn{2}{|c|}{ SW } & \multicolumn{2}{c|}{ ODS } \\
\hline Cited evidence and logical arguments & $\mathrm{N}$ & $\%$ & $\mathrm{~N}$ & $\%$ \\
\hline Cited evidence and logical arguments & 67 & 15.6 & 87 & 19.5 \\
\hline Highlighted the gains made & 21 & 4.9 & 60 & 13.4 \\
\hline Used rhetorical and descriptive logos & 83 & 19.3 & 112 & 25.1 \\
\hline Used wrong guides and incorrect measurements & 189 & 44.1 & 87 & 19.5 \\
\hline Counterfeiting the facts & 69 & 16.1 & 101 & 22.6 \\
\hline Total & 429 & 100 & 447 & 100 \\
\hline
\end{tabular}

The results showed that the NYT often used different strategies to strength its news frame such as to cover the SW, the NYT often used 'wrong guides and incorrect measurements' $(44.1 \%)$, 'rhetorical and descriptive logos' (19.3\%), 'counterfeiting the facts' (16.1\%), 'cited evidence and logical arguments' (15.6\%) and 'highlighted the gains made' $(4.9 \%)$, while covering the ODS, the NYT often used 'rhetorical and descriptive logos' $(25.1 \%)$, 'counterfeiting the facts' $(22.6 \%)$, 'cited evidence and logical arguments', 'used wrong guides and incorrect measurements' (19.5\%) and 'highlighted the gains made' (13.4\%).

The above results were also supported by the qualitative analysis. For example, the NYT was found to use 
more rhetorical and descriptive logos in its news and stories.

"Despite an announcement that the president, Bashar al-Assad, would address the nation on Sunday night, he stayed out of sight, as he has during more than a week of unrest that is threatening his own 11-year presidency and more than 40 years of his family's iron-fisted rule." [Michael Slackman MAR. 27, 2011]

"According to Yemeni viewers, Mr. Hadi offered little reassurance that their long national nightmare was at an end. Many seized on the fact that he read his rambling statement with crooked glasses, and the electricity went off again soon after he finished." [Robert Mackey APR. 21, 2015]

The study also found that the NYT provided some 'wrong guides and incorrect measurements' when covering news and stories related to SW and ODS.

"The Obama administration, seeking new ways to force the Syrian leadership to halt its violent crackdown on domestic dissent, is examining whether war crimes charges can be brought against President Bashar al-Assad, senior administration officials said." [Thom Shanker JUN. 19, 2011]

"Saudi Arabia last intervened in Yemen in 2009. The kingdom was drawn into a fight against the Houthis in support of the central government, then led by Mr. Saleh. Saudi troops suffered more than 130 casualties within a few months." [David D. Kirkpatrick MAR. 26, 2015]

Table 4. Responsibility Frame

\begin{tabular}{|l|c|c|c|c|}
\hline & \multicolumn{2}{|c|}{ SW } & \multicolumn{2}{c|}{ ODS } \\
\hline Causes frame & $\mathrm{N}$ & $\%$ & $\mathrm{~N}$ & $\%$ \\
\hline Causes frame & 116 & 38.7 & 113 & 52.3 \\
\hline Solutions frame & 101 & 33.7 & 38 & 17.6 \\
\hline Results frame & 83 & 27.7 & 65 & 30.1 \\
\hline Total & 300 & 100 & 216 & 100 \\
\hline
\end{tabular}

The NYT often used causes frame (38.7\%) and solutions frame $(33.7 \%)$ to cover the $\mathrm{SW}$, and causes frame $(52.3 \%)$ and results frame $(30.1 \%)$ to cover the ODS.

"The Obama administration, seeking new ways to force the Syrian leadership to halt its violent crackdown on domestic dissent, is examining whether war crimes charges can be brought against President Bashar al-Assad, senior administration officials said.” [Thom Shanker JUN. 19, 2011]

"Doubts about what comes next were widespread, however, given the continued strength of Houthi rebels and forces loyal to former President Ali Abdullah Saleh and a lack of details about what the new Saudi campaign, Operation Restore Hope, would entail." [Robert Mackey APR. 21, 2015]

"The United States and most Arab nations moved quickly to support the Saudi-led operation in Yemen, which Saudi Arabia is calling Operation Decisive Storm. A statement from the White House said that the United States would provide "logistical and intelligence support" to the Saudi-led military operations.” [David D. Kirkpatrick MAR. 26, 2015]

Table 5. Description Terms (SW)

\begin{tabular}{|c|c|c|c|c|c|c|c|c|}
\hline \multicolumn{9}{|c|}{ SW } \\
\hline \multicolumn{3}{|c|}{ President Bashar al-Assad } & \multicolumn{3}{|c|}{ Syrian Army } & \multicolumn{3}{|c|}{ The Opposition } \\
\hline & $\mathrm{N}$ & $\%$ & & $\mathrm{~N}$ & $\%$ & & $\mathrm{~N}$ & $\%$ \\
\hline Terrorist & 32 & 12.0 & Killers & 53 & 23.6 & Rebels & 51 & 24.1 \\
\hline A war criminal & 46 & 17.3 & 'Shabiha' & 42 & 18.7 & Revolutionaries & 89 & 40.6 \\
\hline Tyrannical & 51 & 19.2 & Vicious attackers & 26 & 11.6 & Armed groups & 33 & 15.6 \\
\hline Sectarian & 29 & 10.9 & Vengeance and brutal & 25 & 11.6 & ISIS & 31 & 14.6 \\
\hline Repressive & 41 & 15.4 & al-Assad army & 49 & 32.9 & Extremists & 11 & 5.2 \\
\hline Calm & 9 & 3.4 & Sectarian & 21 & 9.3 & & & \\
\hline President & 39 & 14.7 & Professional army & 9 & 4.0 & & & \\
\hline Brave & 12 & 4.5 & & & & & & \\
\hline Educator & 7 & 2.6 & & & & & & \\
\hline Total & 266 & 100 & & 225 & 100 & & 215 & 100 \\
\hline
\end{tabular}

Two different subjects were linked to cover the SW by the NYT. These were: President Bashar al-Assad, Syrian army and the opposition. The NYT was often describing president Bashar al-Assad as a 'tyrannical' (19.17\%), 'war criminal' (17.29\%), 'repressive' (15.41\%), called him a 'president' (14.66\%), 'terrorist' (12.03\%) and 'sectarian' (10.9\%). In similar way, the NYT often described Syrian army as 'al-Assad army' (32.9 \%\%), 'killers' (23.6\%), 'Shabiha' militia (18.7\%), 'vicious attackers' (11.6\%), 'vengeance and brutal' (11.6\%) and 'sectarian' $(9.3 \%)$. On the other hand, when the NYT described the opposition, it was often referring to them as 'revolutionaries' (40.6\%), 'rebels' (24.1\%), 'armed groups' (15.6\%), 'ISIS' (14.6\%) and 'extremists' (5.2\%).

"'I think Bashar knows there has to be a political solution," said one former European diplomat who spent years in Damascus. "But he doesn't have the courage to do what he needs to do for the sake of 
the country, and perhaps for his own survival.", [Robert F. Worth APR. 24, 2011]

"But activists said Syrian security forces widened their ferocious campaign to crush opposition in the most restive areas, sending troops into Dara'a, the southern town where the protests began a year ago. " [Rick Gladstone MAR. 5, 2012]

"Thousands of Syrians, mostly civilians, have been killed by security forces since the uprising started last March as a peaceful protest against Mr. Assad's autocratic rule, energized by the Arab Spring democracy revolts in Tunisia, Egypt and Libya." [Rick Gladstone MAR. 5, 2012]

Table 6. Description Terms (ODS)

\begin{tabular}{|l|c|l|l|c|c|l|c|c|}
\hline \multicolumn{9}{|c|}{ ODS } \\
\hline \multicolumn{2}{|l|}{ Alliance led SA } & \multicolumn{1}{|c|}{ Yemeni Government (The President) } & \multicolumn{3}{c|}{ The Houthis } \\
\hline & $\mathrm{N}$ & $\%$ & & $\mathrm{~N}$ & $\%$ & & $\mathrm{~N}$ & $\%$ \\
\hline Foolishness & 3 & 21.4 & Powered by SA & 12 & 52.2 & Militias & 41 & 45.1 \\
\hline Brutality & 2 & 14.3 & 'puppet' & 3 & 13.0 & Iranian doll & 14 & 15.4 \\
\hline Sectarianism & 9 & 64.3 & Incompetent & 8 & 34.8 & Sectarian & 25 & 27.5 \\
\hline & & & & & & Killers & 11 & 12.1 \\
\hline Total & 14 & 100 & & 23 & 100 & & 91 & 100 \\
\hline
\end{tabular}

When it comes to cover the ODS, the study found that the NYT divided the issue into two subjects, alliance led by Saudi Arabia (SA), Yemeni government (the president) and the Houthis. The NYT was often describing the alliance led by SA as 'sectarianism' (64.3\%), 'foolishness' (21.4\%) and 'brutality' (14.3\%). Similarly, the Yemeni government was described as 'powered by SA (52.2\%), 'incompetent' (34.8\%) and 'doll' (13\%). The Houthis was described as 'militias' (45.1\%), 'sectarian' (27.5\%), 'Iranian doll' (15.4\%) and 'killers' (12.1\%).

"The uncertainty in Yemen was not assuaged by a televised address from its Saudi-backed president, Abdu Rabbu Mansour Hadi, who spoke from Riaydh, the capital of Saudi Arabia." [Robert Mackey APR. 21, 2015]

"Yemen, is under siege by radical Houthi militia forces whose campaign of horror and destruction is fueled by the political and military support of an Iranian regime obsessed with regional domination. There is no question that the chaos in Yemen has been driven by Iran's hunger for power and its ambition to control the entire region." [Abdu Rabbu Mansour Hadi APR. 12, 2015]

\section{6- Discussion and Conclusion}

Overall, the perceptions of news-sources trends in the NYT regarding the two issues (SW and ODS) can be described as negative trends. The NYT used mainly information, videos, graphics and referrals to highlight the coverage of news and stories, while, in terms of the form of the picture used by the NYT, the results showed that the newspaper used different types of pictures such as feeds/maps, objective pictures and characterized pictures. Both the quantitative and qualitative analysis revealed that the framing perspective of the NYT regarding the SW and ODS was more likely to use emotional features than substantive features to cover all the two issues. The type of frame most used in covering the SW was limited frame, conflict frame, general frame, and humaninterest frame while framing type related to the ODS, the most frame used was conflict frame, human-interest frame, and limited frame.

Finally, 'Transferring facts' for the ODS and 'Provided one view' for the SW, were the most framing mechanisms used by the NYT. Furthermore, to strengthen the news frame the NYT used the 'wrong guides and incorrect measurements' strategy to cover the SW and the 'rhetorical and descriptive logos' strategy to cover the ODS.

\section{References}

Alitavoli, R., (2019). Framing the news on the Syrian War: A comparative study of antiwar.com and cnn.com editorials. Media, War \& Conflict. https://doi.org/10.1177/1750635219850326

Biernatzki, S.J., (2003). War and Media. Communication Research Trends. 22(3), 1-43.

Brown, J. D.J., (2015). "A Nightmare Painted by Goya": Russian Media Coverage of the Syrian Chemical Weapons Attacks in Comparative Perspective. Problems of Post-Communism. 62(4), 236-246. https://doi.org/10.1080/10758216.2015.1026212

Castells, M., (2013). Communication Power. Oxford University Press.

Chong, D., \& Druckman, J. N., (2007). Framing Theory. Annual Review of Political Science., 10, 103-126. https://doi.org/10.1146/annurev.polisci.10.072805.103054

$\begin{array}{lllll}\text { Communication } & \text { Studies. } & \text { June } & \text { Framing } & \text { Theory. }\end{array}$ https://www.communicationstudies.com/communication-theories/framing-theory

Cozma, R., \& Kozman, C., (2015). The Syrian Crisis in the News. Journalism Practice. 9(5), 669-686. https://doi.org/10.1080/17512786.2014.982940

Elzahar, O. M, (2018). Framing the Forgotten War of Yemen: A Comparative Study. The American University in 
Cairo.

Entman, R. M., (1993). Framing: Toward Clarification of a Fractured Paradigm. Journal of Communication. 43(4), 51-58. https://doi.org/10.1111/j.1460-2466.1993.tb01304.x

Godefroidt, A., Berbers, A., \& D'Haenens, L., (2016). What's in a frame? A comparative content analysis of American, British, French, and Russian news articles. The International Communication Gazette. 78(8), 777-801. https://doi.org/10.1177/1748048516640482

Greenwood, K., \& Jenkins, J., (2015). Visual Framing of the Syrian Conflict in News and Public Affairs Magazines. Journalism Studies. 16(2), 207-227. https://doi.org/10.1080/1461670X.2013.865969

Holsti, O.R. (1969). Content Analysis for the Social Sciences and Humanities. Reading, Addison-Wesley.

Karakir, I. R., (2018). Ongoing conflict in Yemen: a proxy war. Turkish Journal of TESAM Academy. 5(2) 141149. https://doi.org/10.30626/tesamakademi.456008

Lee, C. H., (2004). News Coverage of U.S. War With Iraq: A Comparison of The New York Times, The Arab News, and The Middle East Times. University of Texas at Austin.

Lippmann W., (1922). Public Opinion. Harcourt, Brace \& Co.

McCombs, M. E., \& Shaw, D. L., (1972). The Agenda-Setting Function of Mass Media. The Public Opinion Quarterly. 36(2), 176-187.

Meyer, C. O., Sangar, E., \& Michaels, E. (2018). How do non-governmental organizations influence media coverage of conflict? The case of the Syrian conflict, 2011-2014. Media, War \& Conflict. 11(1), 149-171. https://doi.org/10.1177/1750635217727309

Simons, G., (2016). News and Syria: Creating key media moments in the conflict. Cogent Social Sciences. http://dx.doi.org/10.1080/23311886.2016.1170583

Vis, A. S., (2016). Framing the War in Yemen: Narratives of Aggressive Neighbours, Internal Extremism, and Humanitarian Crisis. Utrecht University. 